\title{
An International Pilot Study of K-12 Teachers' Computer Science Self-Esteem
}

\author{
Rebecca Vivian \\ The University of Adelaide \\ Adelaide, South Australia, Australia \\ rebecca.vivian@adelaide.edu.au \\ Katrina Falkner \\ The University of Adelaide \\ Adelaide, South Australia, Australia \\ katrina.falkner@adelaide.edu.au \\ Leonard Busuttil \\ University of Malta \\ Msida, Malta \\ leonard.busuttil@um.edu.mt
}

\author{
Keith Quille \\ TU Dublin \\ Tallaght, Dublin, Ireland \\ keith.quille@TUDublin.ie \\ Sue Sentance \\ Raspberry Pi Foundation \\ Cambridge, England, UK \\ sue@raspberrypi.org \\ Elizabeth Cole \\ University of Glasgow \\ Glasgow, UK \\ e.cole.2@research.gla.ac.uk
}

\author{
Monica M. McGill \\ Knox College \& CSEdResearch.org \\ Galesburg, Illinois, USA \\ mmmcgill@knox.edu \\ Sarah Barksdale \\ University of Minnesota \\ Minneapolis, Minnesota, USA \\ barks016@umn.edu \\ Christine Liebe \\ Colorado School of Mines \\ Golden, Colorado, USA \\ cliebe@mines.edu
}

\author{
Francesco Maiorana \\ Kansas State University \\ Kansas, Manhattan, USA \\ fmaioran@ksu.edu
}

\begin{abstract}
Computer Science (CS) is a new subject area for many K-12 teachers around the world, requiring new disciplinary knowledge and skills. Teacher social-behavioral factors (e.g. self-esteem) have been found to impact learning and teaching, and a key part of CS curriculum implementation will need to ensure teachers feel confident to deliver CS. However, studies about CS teacher self-esteem are lacking. This paper presents an analysis of publicly available data $(n=219)$ from a pilot study using a Teacher CS Self-Esteem scale. Analysis revealed significant differences, including 1) females reported significantly lower CS self-esteem than males, 2) primary teachers reported lower levels of CS self-esteem than secondary teachers, 3) those with no CS teaching experience reported significantly lower CS self-esteem, 4) teachers with 0-3 years experience had a negative CS self-esteem, but after four years, teachers had a positive CS self-esteem, and 5) teachers who lived further from metropolitan areas and in some countries reported lower CS self-esteem. These initial findings suggest a pressing need for future research to look further into teacher CS self-esteem to inform teacher CS professional development.
\end{abstract}

\footnotetext{
Permission to make digital or hard copies of all or part of this work for personal or classroom use is granted without fee provided that copies are not made or distributed for profit or commercial advantage and that copies bear this notice and the full citation on the first page. Copyrights for components of this work owned by others than ACM must be honored. Abstracting with credit is permitted. To copy otherwise, or republish, to post on servers or to redistribute to lists, requires prior specific permission and/or a fee. Request permissions from permissions@acm.org.

ITiCSE '20, June 15-19, 2020, Trondheim, Norway

(C) 2020 Association for Computing Machinery.

ACM ISBN 978-1-4503-6874-2/20/06 . \$ \$15.00

https://doi.org/10.1145/3341525.3387418
}

\section{KEYWORDS}

Computer Science Education,Teachers, K-12 Teachers, Self-esteem

ACM Reference Format:

Rebecca Vivian, Keith Quille, Monica M. McGill, Katrina Falkner, Sue Sentance, Sarah Barksdale, Leonard Busuttil, Elizabeth Cole, Christine Liebe, and Francesco Maiorana. 2020. An International Pilot Study of K-12 Teachers' Computer Science Self-Esteem. In Proceedings of the 2020 ACM Conference on Innovation and Technology in Computer Science Education (ITiCSE '20), June 15-19, 2020, Trondheim, Norway. ACM, New York, NY, USA, 7 pages. https://doi.org/10.1145/3341525.3387418

\section{INTRODUCTION}

Many countries offer or integrate Computer Science (CS) curriculum into K-12 education [1, 13, 22]; however, recently the introduction of CS into primary and secondary years curricula has been a completely new discipline for many teachers in a number of countries $[3,7,14,15,17,34,40]$. This presents new challenges in terms of supporting teachers and schools to implement new curricula into classrooms as well as preparing teachers to build their knowledge and skills in a completely new discipline area. To date, many teachers have not encountered CS within their formal teacher education training and experiences [11]. Significant effort is being undertaken to determine best ways to build teacher capacity in teaching CS, with a recognised need to support teachers with varying degrees of background skills, knowledge, confidence, perceptions and identity [27, 28].

A thorough search of computing teacher self-esteem in previous studies could not be found, indicating that this is a factor that remains unexplored. Further, a majority of computing education research studies investigates teacher professional development (PD) and experience at national level rather than examining the experiences and self-perceptions of teachers across countries. This gap 
led us to explore the following research question: What are the differences in K-12 teachers' CS self-esteem compared across countries, year groups taught, experience teaching CS, gender and age?

This pilot study is important for PD curriculum designers and providers as well as administrators and overseeing bodies that are responsible for engaging teachers in PD. If differences are found across countries, for example, we can further examine why these differences exist and determine if changes to PD may strengthen CS self-esteem in countries where it is weaker. Likewise, if teachers in various age, gender, or year levels groups are shown to have various levels of self-esteem, we can begin the process of determining why this is to see how PD can be modified to address this important concept. Further, we can begin to analyze the scale used for this measurement to determine if it has evidence of validity and reliability so that it can used in future studies.

\section{BACKGROUND}

To frame this work, in this section we provide a discussion around CS self-esteem and closely related constructs of self-concept and self-efficacy, followed by related research.

\subsection{Self-esteem and related constructs}

Self-esteem is an attitude about the self and is related to personal beliefs and judgements about skills, abilities, social relationships, and future outcomes $[4,23]$ and the extent to which the individual believes themselves to be capable, significant, successful, and worthy [12] (pp. 4-5). The term self-esteem has been used interchangeably with self-concept, self-worth and self-efficacy with a lack of agreement and consistency about the constructs themselves in the literature $[4,10]$, and variations in the way researchers define the constructs within and across disciplines [44].

However, authors have drawn subtle distinctions, with selfconcept as being about a more general, higher-level construct referring to a person's perception of oneself and one's traits [41]. It is 'the totality of cognitive beliefs that people have about themselves... everything that is known about the self' (e.g. race, likes, dislikes, values, appearance descriptions), whereas self-esteem is '..the emotional response that people experience as they contemplate and evaluate different things about themselves'(p.220) [23].

Educational psychology researchers are particularly interested in domain-specific self-concept or self-esteem, which is a person's self-evaluation regarding a specific domain or ability in academic areas, typically through self-reported measures [44]. Similarly, performance self-esteem is one's sense of general competence and includes intellectual abilities, performance, self-regulatory capacities, confidence, efficacy, and agency [23].

Similarly, self-esteem and self-efficacy are closely related constructs, but we recognise differences as cited in the literature. Selfesteem is more broadly concerned with a person's positive and negative attitudes or perceptions about their self [38], and within particular domains [44], whereas self-efficacy is much more taskspecific and is concerned with a person's belief in their own capabilities to execute specific tasks [6]. To demonstrate these construct differences, we present a similar statement in different ways below:

- I feel that I have a number of good qualities (global selfesteem, as seen in [38]).
- I feel that I have a number of good Java programming qualities (domain specific self-esteem, as seen in [8]).

- I can write syntactically correct programming statements (self-efficacy, as seen in [8]).

In terms of measurement, [38] defines what an individual perceives as "good enough" in their self-evaluation; however, [38] defines high self-esteem as being at a satisfactory level and a person with high self-esteem as having self-worth and respect for themselves. Low self-esteem is aligned with a person feeling rejection in themselves, dissatisfaction and low self-worth. Coopersmith [12] argues that individuals with high self-esteem are more effective, active, and assertive in meeting environmental demands whereas those with low-self esteem withdraw, which could have implications for teachers implementing new CS curriculum.

\subsection{Related work}

Numerous studies to date have examined students' self-efficacy in CS. Ramalingam and Wiedenbeck [36] were among the first researchers to develop a self-efficacy scale for programming courses. This self-efficacy scale has been adapted by other researchers to explore the relationship between self-efficacy and students' performance $[2,24,48]$, and high self-efficacy and a good mental model are important to knowledge acquisition and transfer. Another study by Ramalingam et al. investigating the effects of students' selfefficacy and mental models on learning to program showed that self-efficacy is 1) influenced by previous programming experience and 2) increases as a student progresses through an introductory programming course [35]. The results also showed that students' mental model of programming influences self-efficacy and that both the mental model and self-efficacy affect course performance.

Specific studies about teaching computing have shown interesting results, such as the use of the peer instruction approach having a positive impact on undergraduate CS self-efficacy [51]. Another study in K-12 looking at computational thinking has shown correlations between computational thinking skill (measured by a programming test) and perceptions of self-efficacy [37].

Although self-efficacy has been investigated in CS, limited research has explored CS self-esteem, despite it playing a role in academic achievement. In a $\mathrm{PhD}$ study by Bergin [9], programming self-esteem was found to be a strong predictor of programming performance. A follow-on study with 693 undergraduate CS1 students [33] discovered significant differences in reported programming self-esteem according to variables like age and gender.

In learning situations, self-efficacy influences the amount of effort expended, type of coping strategies adopted, use of cognitive strategies while solving problems, persistence in the face of failure, and performance outcomes [5]. This is key for teachers. For teachers, the combination of successful past experience; verbal support from principals, students, peers, and parents; and opportunities for observation of successful peers builds self-efficacy for teaching [45]. Teacher self-efficacy may be conceptualised as an individual teacher's beliefs in their own abilities to plan, organize, and carry out activities required to attain given educational goals [42].

Teacher self-efficacy is linked with job satisfaction, but does not necessarily correlate with years of experience [25], particularly with relation to classroom management efficacy. Several studies 
have investigated the relationship between teacher self-efficacy and burn-out [43], yet, there is limited research available in regard to teacher self-efficacy and CS. Research by Yukselturk and Altiok [50] investigated pre-service teacher self-efficacy following exposure to Scratch programming in their courses. They discovered significant increases in the mean of the teachers' self-efficacy perceptions regarding almost all complex programming tasks after their Scratch programming experience. The results also showed that the teachers' negative attitudes towards programming decreased significantly.

When referring to CS and teachers, self-efficacy and CS selfesteem are likely to be affected by the amount of time teachers have been learning the subject themselves. For example, a study of computing pre-service teachers showed that they had higher self-efficacy around inquiry and problem-solving skills than for programming [52]. This is not surprising if they are relatively new to programming. A study looking at challenges faced by CS teachers found that teachers initially struggle with teaching CS because of their limited content knowledge [49], and this is likely to impact their self-efficacy. Further, an Australian study reported that teacher experience in engaging in assessment practices in the CS classroom impacted their self-efficacy [47]. Although research has explored teacher self-efficacy in CS, as far as we are aware, there are no specific studies investigating teacher CS self-esteem.

\section{METHODOLOGY}

The MEasuring TeacheR Enacted Computing Curriculum (METRECC) Instrument was developed and (publicly available) pilot data was collected as part of an ITICSE working group [18, 21].

\subsection{The METRECC Instrument}

METRECC was created to establish a benchmark of enacted K-12 education internationally $[18,21]$. The instrument has been designed with evidence of validity and reliability to measure several facets such as intended and enacted curriculum and included a Teacher CS Self-Esteem scale. This scale utilised the Bergin Self-Esteem Instrument [8] that was developed as part of a longitudinal study. Bergin developed the scale as a modification of the Rosenberg self-esteem scale [39] to apply to programming. The Rosenberg self-esteem scale is said to be the most widely used self-esteem measure in social science research [8] and has been shown to have generally high inter-item and test-retest reliability evidence [39]. The 10 items used in the Bergin [8] study were added to the METRECC instrument; however, the domain-specific subject was adapted from 'programming' to 'Computer Science' to reflect the broader K-12 CS curriculum that the survey was investigating, beyond 'programming' knowledge and skills (see Table 3).

Teachers responded to statements on a 7-point Likert scale, from 1 (Strongly Disagree) to 7 (Strongly Agree). Principle Component Analysis (PCA) was used to reduce the 10 items from the CS selfesteem instrument to one principal component, thus obtaining a single value to accurately represent CS self-esteem [8, 32]. The PCA algorithm produced a single value where a teacher with high CS self-esteem is reported as a negative PCA value $(P C A<0.0)$, while a teacher with a low CS self-esteem is reported as positive $(P C A>0.0)$. For evidence of reliability and validity, Cronbach's $\alpha=89.04$ indicates good reliability [21]. The entire instrument, including the CS self-esteem scale, was measured for validity using
Table 1: Participants per country and age ranges.

\begin{tabular}{|c|c|c|c|c|c|}
\hline Country & $\mathbf{N}$ & $\%$ & Age Range & $\mathbf{N}$ & $\%$ \\
\hline USA & 98 & 45 & $18-29$ & 7 & 3 \\
\hline England & 49 & 22 & $30-39$ & 52 & 24 \\
\hline Italy & 18 & 8 & $40-49$ & 70 & 32 \\
\hline Ireland & 19 & 9 & $50-59$ & 70 & 32 \\
\hline Scotland & 17 & 8 & 60 or over & 20 & 9 \\
\hline Australia & 14 & 6 & \multirow[t]{3}{*}{ Total } & \multirow[t]{3}{*}{219} & \multirow[t]{3}{*}{100} \\
\hline Malta & 4 & 2 & & & \\
\hline Total & 219 & 100 & & & \\
\hline
\end{tabular}

construct (measured by face and concurrent validity), population, and sampling validity, as thoroughly reported in [21].

\subsection{Data Collection and analysis}

The pilot of the METRECC survey was administered via Survey Monkey and open for two weeks (30th June-12th July, 2019) [18, 21]. The authors used social media to find participants, sharing it with organizations in their respective countries that support teachers teaching computing (e.g., Computer Science Teachers Association) and/or deliver PD. Further details can be found in $[18,21]$. The survey instrument and dataset can be found online ${ }^{1}$.

The survey collected non-identifiable teacher data. Data from the survey were imported into Excel for analysis using a combination of scripts in Python and the statistical software package, SPSS Statistics. To answer our research question What are the differences in K-12 teachers' CS self-esteem compared across countries, year groups taught, experience teaching CS, gender and age?, we conducted several comparisons with K-12 teachers based on their CS self-esteem values and examined teachers' reported CS self-esteem by: country, teacher age, the ages of students that the teachers teach (teaching age groups), the location (e.g., urban, metro, rural) that the teachers teach in, experience in teaching CS and teacher gender. We present the results for each category in the following sections. The statistical methods adopted to investigate the research questions are presented with the results in section 4 .

\subsection{Teacher Demographics}

The majority of participants $(67 \%)$ in the pilot study were from the U.S. $(n=98)$ and England $(n=49)$. Italy, Ireland, and Scotland comprised $25 \%$ of the sample, and Australia and Malta comprised $8 \%$ of participants (see Table 1). The study also reported a larger female representation from most countries $(61 \%)$, with Scotland being the only country with more male respondents $(n=10)$ than female $(n=7)$, as presented in Table 2 . Some $64 \%$ of teachers were between the ages of $40-59$ and $24 \%$ were between $30-39$ years (see Table 1). Each participant agreed to publish their data, thus allowing for other researchers to conduct further analysis of the data.

\section{RESULTS}

Table 3 presents the items that comprise the CS self-esteem scale along with overall means for the sample. Teachers reported higher levels of agreement towards positive statements than negative;

\footnotetext{
${ }^{1}$ https://csedresearch.org/tool/?id=185
} 
Table 2: Gender breakdown per country.

\begin{tabular}{lllllll}
\hline & \multicolumn{2}{c}{ Male } & \multicolumn{2}{c}{ Female } & \multicolumn{2}{c}{ Prefer not to say } \\
\hline Country & $\mathrm{N}$ & $\mathbf{\%}$ & $\mathrm{N}$ & $\mathbf{\%}$ & $\mathrm{N}$ & $\mathbf{\%}$ \\
\hline USA & 33 & $\mathbf{3 4 \%}$ & 63 & $\mathbf{6 3 \%}$ & 2 & $\mathbf{2 \%}$ \\
England & 22 & $\mathbf{4 5 \%}$ & 26 & $\mathbf{5 3 \%}$ & 1 & $\mathbf{2 \%}$ \\
Italy & 8 & $\mathbf{4 0 \%}$ & 11 & $\mathbf{5 8 \%}$ & 0 & $\mathbf{0 \%}$ \\
Ireland & 6 & $\mathbf{3 3 \%}$ & 12 & $\mathbf{6 7 \%}$ & 0 & $\mathbf{0 \%}$ \\
Scotland & 10 & $\mathbf{5 9 \%}$ & 7 & $\mathbf{4 1 \%}$ & 0 & $\mathbf{0 \%}$ \\
Australia & 2 & $\mathbf{1 4 \%}$ & 11 & $\mathbf{7 9 \%}$ & 1 & $\mathbf{7 \%}$ \\
Malta & 1 & $\mathbf{2 5 \%}$ & 3 & $\mathbf{7 5 \%}$ & 0 & $\mathbf{0 \%}$ \\
\hline Total & 82 & $\mathbf{3 7 \%}$ & 133 & $\mathbf{6 1 \%}$ & 4 & $\mathbf{2 \%}$ \\
\hline
\end{tabular}

however, statements relating to having respect for their CS ability were closer to a neutral level of agreement. Here we examine these differences across categories more closely.

Table 3: Reported teacher CS self-esteem against items.

\begin{tabular}{lll}
\hline Item & M & SD \\
\hline I take a positive attitude towards my CS ability. & 6.1 & 1.2 \\
I feel that I am a person of worth, at least on a (level) plane with & 6.0 & 1.3 \\
other colleagues. & & \\
I am able to complete CS tasks as well as most other colleagues. & 5.9 & 1.4 \\
I feel that I have a number of good CS qualities. & 5.7 & 1.3 \\
On the whole, I am satisfied with my CS progress. & 5.5 & 1.5 \\
I wish I could have more respect for my CS ability. & 3.5 & 2.2 \\
At times, I think that I am no good at all at CS. & 2.9 & 1.8 \\
I certainly feel useless at CS at times. & 2.4 & 1.7 \\
I feel that I do not have much CS ability to be proud of. & 2.3 & 1.7 \\
All in all, I am inclined to feel that I am a failure at CS. & 1.7 & 1.4 \\
\hline
\end{tabular}

\subsection{Country}

A comparison was conducted of CS self-esteem across the seven countries (see Table 4). Though the majority of responses were from the U.S. and England ( $n=67 \%$ ), given the differences in student populations, responses from the U.S. were underrepresented.

Table 4: Average teacher CS self-esteem by Country.

\begin{tabular}{lcc}
\hline Country & CS self-esteem & SD \\
\hline Australia & +0.3186 & 4.1305 \\
England & -0.4981 & 3.2869 \\
Ireland & +0.9295 & 3.2897 \\
Italy & -0.5448 & 2.4688 \\
Malta & +1.2059 & 2.3013 \\
Scotland & -1.2752 & 3.0671 \\
USA & +0.2954 & 3.9872 \\
\hline
\end{tabular}

There were no statistically significant differences between group means as determined by one-way ANOVA $(F(6,212)=0.9949, p=$ 0.4297). A Tukey HSD post-hoc test was performed to confirm the findings, with no statistically significant differences reported between any country groups. Only England, Italy and Scotland show a positive CS self-esteem (negative values correspond to a positive CS self-esteem). While further work is required to unpack this finding, the differences could be due to each country's intended and enacted curriculum [19].

\subsection{Teacher Age}

Age of students has previously shown to be a factor when predicting success of undergraduates in CS1 [29,31]. When age was examined it was hypothesised that younger students (in particular males), overrated their CS self-esteem and older students may underrate theirs. We examined the K-12 teacher data to determine if our data was similar (see Table 5). Our results reveal there were no statistically significant differences between group means as determined by one-way ANOVA $(F(4,214)=1.5485, p=0.1893)$. A Tukey HSD post-hoc test was also performed to confirm the findings, with no statistically significant differences reported between any age groups. While the differences were not statistically significant, some differences were detected (see Figure 1).

Table 5: Average CS self-esteem by age

\begin{tabular}{lcc}
\hline Age & CS self-esteem & SD \\
\hline $18-29$ & -1.6995 & 5.10 \\
$30-39$ & +0.7707 & 3.66 \\
$40-49$ & +0.2403 & 3.62 \\
$50-59$ & -0.5758 & 3.29 \\
60 or over & -0.2346 & 3.67 \\
\hline
\end{tabular}

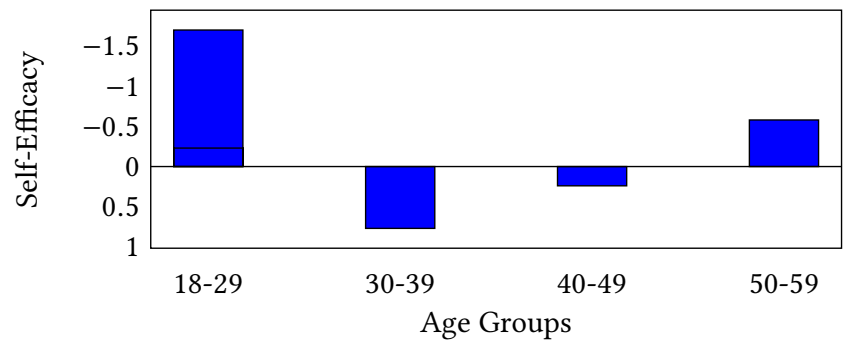

Figure 1: Teacher CS self-esteem by age. Negative values represent higher CS self-esteem ( $y$-axis reversed to reflect this).

An interesting finding is that teachers between 30-49 have the lowest CS self-esteem. Though the sample size of teachers in the 18-29 age group is relatively small, they have the most positive CS self-esteem. Teachers 50 or older also present a higher positive CS self-esteem to that of the 30-49 group. This could suggest a need to focus PD towards specific age groups, however, further work is required to investigate reasons for these age-related variations.

\subsection{Teacher CS Experience}

Mastering CS at the industry level takes $\approx 10,000$ hours or five full time working years [26]. We investigated to see if years of experience teaching CS supported this (Table 6). We found a statistically significant difference between group means as determined by one-way ANOVA $(F(6,212)=7.0471, p=0.0000)$. A Tukey HSD post-hoc test was also performed and the only statistical difference was between the "No experience group" and all other groups (Table 7). This was expected as K-12 teachers that have not taught a formal CS class would not be expected to have a high CS self-esteem. We 
Table 6: Average CS self-esteem teaching experience. Negative values represent higher CS self-esteem.

\begin{tabular}{lccc}
\hline CS Experience & CS self-esteem & SD & N \\
\hline 0 (None) & +4.8586 & 4.58 & 14 \\
1 (First Year) & +0.6489 & 3.25 & 17 \\
$2-3$ & +0.9664 & 3.90 & 41 \\
$4-5$ & -0.4761 & 3.14 & 48 \\
$6-10$ & -0.9787 & 2.84 & 44 \\
$11-15$ & -0.8177 & 3.13 & 27 \\
16 or more & -0.9177 & 3.01 & 28 \\
\hline
\end{tabular}

also found that teachers with $0-3$ years experience teaching CS have a negative CS self-esteem (positive values in Figure 2), and after four years, teachers have a positive CS self-esteem. This suggests that teachers require four years or more to develop a positive CS self-esteem. Further work is required to validate this finding, since it may behoove PD teachers to explain this to teachers and for those adopting new curricula (e.g. growth mindset).

Table 7: CS self-esteem teaching experience, Tukey HSD post-hoc analysis with $p$-values (CI 95\%)

\begin{tabular}{lccccccc}
\hline & None & $\mathbf{1}$ & $\mathbf{2}-\mathbf{3}$ & $\mathbf{4}-\mathbf{5}$ & $\mathbf{6 - 1 0}$ & $\mathbf{1 1}-\mathbf{1 5}$ & $\mathbf{1 6}+$ \\
\hline None & - & 0.0101 & 0.0039 & $<0.0000$ & $<0.0000$ & $<0.0000$ & $<0.0000$ \\
$\mathbf{1}$ & 0.0101 & - & 0.9999 & 0.8954 & 0.6110 & 0.7905 & 0.7280 \\
$\mathbf{2}-\mathbf{3}$ & 0.0039 & 0.9999 & - & 0.3967 & 0.1067 & 0.3230 & 0.2470 \\
$\mathbf{4}-\mathbf{5}$ & $<0.0000$ & 0.8954 & 0.3967 & - & 0.9911 & 0.9995 & 0.9970 \\
$\mathbf{6 - 1 0}$ & $<0.0000$ & 0.6110 & 0.1067 & 0.9911 & - & 1.0000 & 1.0000 \\
$\mathbf{1 1}-\mathbf{1 5}$ & $<0.0000$ & 0.7905 & 0.3230 & 0.9995 & 1.0000 & - & 1.0000 \\
$\mathbf{1 6}+$ & $<0.0000$ & 0.7280 & 0.2470 & 0.9979 & 1.0000 & 1.0000 & - \\
\hline
\end{tabular}

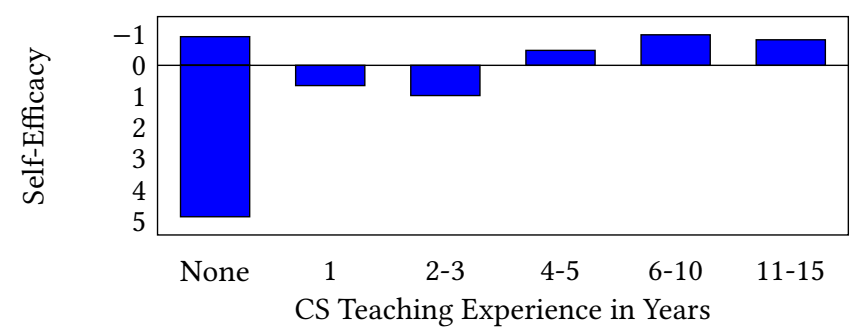

Figure 2: Teacher CS self-esteem based on CS teaching experience. Negative values represent higher CS self-esteem (y-axis reversed to reflect this).

\subsection{Teaching Age Groups}

The survey invited teachers to select check-boxes for each year level they currently teach CS for, with the age groupings being: Pre-primary (3-5 years); Junior Primary (6-7 years); Primary (810 years); Upper Primary (11-12 years); Lower Secondary (13-15 years); Secondary (16-17 years) and Senior Secondary (18-19 years). Teachers could select more than one and some teachers identified as teaching both primary and secondary. For the purpose of this study, teachers were classified by either primary or secondary level
Table 8: Average CS self-esteem by teaching groups. Negative values represent higher CS self-esteem

\begin{tabular}{lccr}
\hline Group & CS self-esteem & SD & N \\
\hline Primary Level & +1.0917 & 4.20 & 56 \\
Second Level & -0.3550 & 3.30 & 163 \\
\hline
\end{tabular}

Table 9: Average CS self-esteem by teaching location. Negative values represent higher CS self-esteem.

\begin{tabular}{lccr}
\hline Group & CS self-esteem & SD & N \\
\hline Metro & -0.6028 & 3.36 & 41 \\
Urban & +0.0367 & 3.48 & 106 \\
Rural & +0.2698 & 3.82 & 60 \\
Remote & +1.5121 & 2.59 & 3 \\
\hline
\end{tabular}

(binomial), by identifying which year level ranges they primarily taught within (Table 8).

The difference is statistically significant with primary teacher reporting lower self-esteem than secondary teachers $(p=0.0199$ at $95 \%$ confidence interval using a Welch's $t$ - test). This finding could be of value to the CS PD community to understand why primary school teachers have significantly lower CS self-esteem than secondary teachers. Future studies could compare the level of CS required for primary and second level teachers (where secondary content and depth would be significantly more advanced), determining if the depth of content required and prior exposure at these varying levels influences teacher CS self-esteem.

\subsection{Teaching Location}

The METRECC instrument included several location options to select the teaching setting in which they teach (Metro (City, CBD), Urban (Suburbs surrounding city), Rural, Remote and Other). As the "Other" option $(n=9)$ accounted for $\sim 4 \%$ of the participants and it may be that they were not teaching, this category was excluded from this analysis, due to its uncertainty.

The results are presented in Table 9. There were no statistically significant differences between location group means as determined by one-way $\operatorname{ANOVA}(F(3,206)=0.6932, p=0.5572)$. A Tukey HSD post-hoc test was also performed, with no statistically significant differences reported between any location groups. While there was no statistically significant difference, Figure 3 suggests that the further teachers live from city centres (Metro) the less CS self-esteem they report. This may be due to factors such as PD availability, teacher networks or resources but additional research is required.

\subsection{Gender}

Previous work examining programming self-esteem of male and female undergraduate students in CS1 courses [33] found that female students, despite having multiple positive factors such as higher mathematical grades prior to commencing CS1, had significantly less programming self-esteem than males. Additionally, females showed less than neutral, negative programming self-esteem, whereas males had a positive programming self-esteem. Female 


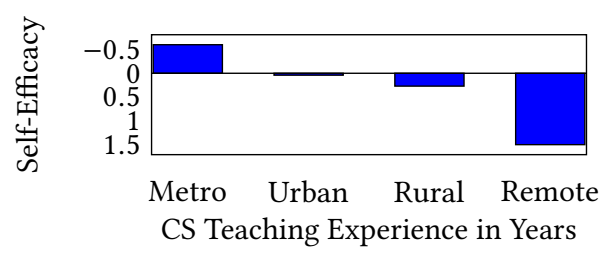

Figure 3: Teacher CS self-esteem based on teaching location. Negative values represent a higher CS self-esteem (y-axis reversed to reflect this).

Table 10: Average CS self-esteem by gender. Negative values represent higher CS self-esteem.

\begin{tabular}{lccc}
\hline Group & CS self-esteem & SD & N \\
\hline Male & -0.7628 & 3.89 & 82 \\
Female & +0.5036 & 2.98 & 133 \\
\hline
\end{tabular}

students underrated their programming self-esteem compared to their CS1 performance, and males overrated theirs. While this study only examines teacher self-esteem, a similar pattern emerged as seen in Table 10. "Prefer not to say" was not included since this group accounted for $2 \%$ of the participants (as reported in Table 2).

A Welch's $t$-test was conducted to investigate the differences between the means of CS self-esteem between the two groups reporting a $p$-value of 0.01265 . The difference in CS self-esteem reported is statistically significant. These findings align with the aforementioned research [33] (although this study had no metric to examine teacher performance) and prompts questions for future research, such as: "Are male teachers overrating their CS self-esteem, while female teachers underrate theirs?" and "If males and females correctly rate their CS self-esteem, why do female teachers have significantly lower CS self-esteem than males?"

\section{DISCUSSION}

Our analysis revealed significant differences in teacher CS selfesteem according to gender, teaching experience and year level taught. Females reported lower CS self-esteem than males and those with no CS teaching experience reported significantly lower CS selfesteem than other groupings. There were also significant differences between primary and secondary teachers, with primary teachers reporting significantly lower levels of CS self-esteem. Although no significant differences among age groups, locations or countries were identified, our results suggest that teachers 30-39 years of age and teachers living further from metropolitan areas or in Scotland, England and Italy show a more positive CS self-esteem than others.

As was recommended in prior research for pre-service teachers [16], our findings have implications for teacher training in CS, urging a need for PD design and training to address teacher self-doubt and positive perceptions of the self in CS. Additionally, findings suggests targeted consideration is required toward particular cohorts of teachers, such as primary teachers, females and those working in rural or remote communities.

Although no previous studies were found that measure teacher CS self-esteem, our results are similar to those found in [47] that suggests teacher self-efficacy in CS increases over time with experience and [16], which found that self-esteem fluctuates over time, impacting teaching, coping ability, interactions with students, and more. Likewise, [30] found that CS self-esteem of undergraduate CS1 students fluctuated based on age and gender, similarly, with males showing higher self-esteem than females. Additionally, the authors performed a deeper analysis, finding that while female CS1 students showed lower self-esteem and higher test anxiety than male students, female students out-performed male students and with lower attrition rates. This could also attribute to the future direction of this work, to examine additional factors such as teacher retention or subject selection (if it was a choice to teach CS).

\subsection{Limitations}

Since this is a pilot study with the authors' intent to engage in a larger-scale study, the results reflect a much smaller number of participants $(n=219)$ than what is needed to be able to generalize across multiple countries. We recognize that the results are, in essence, a teaser of what we can explore further in order to generalize to the broader CS teacher community. Qualitative data could also contribute to a better understanding of why these differences exist.

Content in CS curriculum may vary (and in fact does, as shown in [20]), and this may be reflected in the differences that are being seen in these results. Further, variables may be conflated. For example, in the U.S., $89 \%$ of those who teach primary grades are women [46], so there could be conflation among the U.S. responses and the female responses. Further studies with a much larger pool of participants (e.g., $n>=2000$ ) should control for these variables.

Item wording may also have influenced teachers, particularly those at the primary level, since these teachers may be more familiar with the phrase "computational thinking" rather than "computer science". This could have affected the results and will be addressed in a revision of the instrument prior to the larger scale study.

Finally, a major contribution of this work to the larger CS education research community is the Teacher CS Self-Esteem Scale. Though we provide only an pilot summary of the scale in this study, an ongoing parallel study further investigates this scale as reusable.

\section{CONCLUSIONS}

CS self-esteem has been previously been found to impact learning and teaching. It is worth further study to determine factors that influence CS self-esteem beyond categories investigated in this study (e.g., PD engagement, resources, school support and networks). Future work can expand the administration of the survey across more countries, with larger samples and to monitor changes in CS selfesteem over time. The results of this initial study have identified key areas for further in-depth exploration in teacher CS self-esteem. This work also yields further research questions, such as "What interventions or PD can improve teacher CS self-esteem and particularly for cohorts with significantly lower CS self-esteem?" And, if it takes years to master CS in industry, how long does it take teachers to build CS self-esteem and what impact does low teacher CS self-esteem have on student learning in CS? Future research could also examine these efforts and PD for countries with higher CS self-esteem and to trial and evaluate PD design and training interventions that aim to develop positive CS self-esteem. 


\section{REFERENCES}

[1] M. M. Al-Sulaiman. A computing curriculum for technical high schools in the kingdom of saudi arabia. F. King Saud Univ. Comput. Inf. Sci., 11:85-104, Jan. 1999.

[2] P. Askar and D. Davenport. An investigation of factors related to self-efficacy for java programming among engineering students. Online Submission, 8(1), 2009.

[3] Australian Curriculum, Assessment and Reporting Authority (ACARA). Australian Curriculum: Digital Technologies. http://www.australiancurriculum.edu.au/, 2015.

[4] J. A. Bailey. The foundation of self-esteem. Fournal of the National Medical Association, 95(5):388-393, 2003.

[5] A. Bandura. Self efficacy. In V. S. Ramachaudran, editor, Encyclopedia of human behavior, volume 4, pages 71-81. New York: Academic Press, 1994

[6] A. Bandura, W. Freeman, and R. Lightsey. Self-efficacy: The exercise of control, 1999.

[7] T. Bell, P. Andreae, and A. Robins. A case study of the introduction of computer science in NZ schools. ACM Transactions on Computing Education, 14:1-31, 2014

[8] S. Bergin. A computational model to predict programming performance. $\mathrm{PhD}$ thesis, Department of Computer Science, Maynooth University, 2006.

[9] S. Bergin and R. Reilly. Programming: Factors that influence success. SIGCSE Bull., 37(1):411-415, February 2005.

[10] J. D. Brown and M. A. Marshall. The three faces of self-esteem. In Self-Esteem Issues and Answers. 2006

[11] N. C. C. Brown, S. Sentance, T. Crick, and S. Humphreys. Restart: The resurgence of computer science in uk schools. ACM Trans. Comput. Educ., 14(2):9:1-9:22, June 2014.

[12] S. Coopersmith. The antecedents of self-esteem. Freeman, San Francisco, 1967.

[13] V. Dagiene. Teaching information technology and elements of informatics in lower secondary schools: Curricula, didactic provision and implementation. In Proceedings of the 3rd International Conference on Informatics in Secondary Schools - Evolution and Perspectives: Informatics Education - Supporting Computational Thinking, ISSEP '08, pages 293-304, Berlin, Heidelberg, 2008. Springer-Verlag.

[14] Department for Education. The National Curriculum in England. Department for Education Government of UK, Crown, Cheshire, 2013.

[15] Directorate for Learning and Assessment Programmes. SEC Syllabus (2019) Computing. 2019.

[16] R. Dobbins. Student teacher self-esteem in the practicum. Australian fournal of Teacher Education, 21(2), 111996.

[17] Education Scotland. Benchmark technologies. https://education.gov.scot/improvement/documents/technologiesbenchmarkspdf.pdf, 2017.

[18] K. Falkner, S. Sentance, R. Vivian, S. Barksdale, L. Busuttil, E. Cole, C. Liebe, F. Maiorana, M. M. McGill, and K. Quille. An international benchmark study of k-12 computer science education in schools. In Proceedings of the 2019 ACM Conference on Innovation and Technology in Computer Science Education, ITiCSE '19, pages 257-258, New York, NY, USA, 2019. ACM.

[19] K. Falkner, S. Sentance, R. Vivian, S. Barksdale, L. Busuttil, E. Cole, C. Liebe, F. Maiorana, M. M. McGill, and K. Quille. An international comparison of k-12 computer science education intended and enacted curricula. In Proceedings of the 19th Koli Calling International Conference on Computing Education Research, Koli Calling '19, New York, NY, USA, 2019. Association for Computing Machinery.

[20] K. Falkner, S. Sentance, R. Vivian, S. Barksdale, L. Busuttil, E. Cole, C. Liebe, F. Maiorana, M. M. McGill, and K. Quille. An international comparison of k-12 computer science education intended and enacted curricula. In Proceedings of the 19th Koli Calling International Conference on Computing Education Research Koli Calling '19, pages 4:1-4:10, New York, NY, USA, 2019. ACM.

[21] K. Falkner, S. Sentance, R. Vivian, S. Barksdale, L. Busuttil, E. Cole, C. Liebe, F. Maiorana, M. M. McGill, and K. Quille. An international study piloting the measuring teacher enacted computing curriculum (metrecc) instrument. In Proceedings of the Working Group Reports on Innovation and Technology in Computer Science Education, ITiCSE-WGR '19, page 111-142, New York, NY, USA, 2019. Association for Computing Machinery.

[22] J. Gal-Ezer, C. Beeri, D. Harel, and A. Yehudai. A high school program in computer science. Computer, 28(10):73-80, Oct. 1995.

[23] T. F. Heatherton and C. L. Wyland. Assessing self-esteem. In Positive psychological assessment: A handbook of models and measures. 2004

[24] G. Kanaparan, R. Cullen, and D. Mason. Effect of self-efficacy and emotional engagement on introductory programming students. Australasian fournal of Information Systems, 23, 2019.

[25] R. M. Klassen and M. M. Chiu. Effects on teachers' self-efficacy and job satisfaction: [teacher] gender, years of experience, and job stress. Fournal of Educational Psychology, 102(3):741-756, 2010. 01615.

[26] P. Morrison and E. Murphy-Hill. Is programming knowledge related to age? an exploration of stack overflow. In Proceedings of the 10th Working Conference on Mining Software Repositories, MSR '13, pages 69-72, Piscataway, NJ, USA, 2013 IEEE Press.
[27] L. Ni and M. Guzdial. Who am i?: Understanding high school computer science teachers' professional identity. In Proceedings of the 43rd ACM Technical Symposium on Computer Science Education, SIGCSE '12, pages 499-504, New York, NY, USA, 2012. ACM

[28] L. Pollock, C. Mouza, A. Czik, A. Little, D. Coffey, and J. Buttram. From professional development to the classroom: Findings from cs k-12 teachers. In Proceedings of the 2017 ACM SIGCSE Technical Symposium on Computer Science Education, SIGCSE '17, pages 477-482, New York, NY, USA, 2017. ACM.

[29] K. Quille and S. Bergin. Programming: Further factors that influence success. Psychology of Programming Interest Group (PPIG), 7th to 10th Spetember, University of Cambridge, 2016.

[30] K. Quille and S. Bergin. Programming: Further factors that influence success. In $P P I G$, page 14, 2016

[31] K. Quille and S. Bergin. Programming : Predicting Student Success Early in CS1 . A Re-validation and Replication Study. In Proceedings of the 23rd Annual ACM Conference on Innovation and Technology in Computer Science Education (ITiCSE'18), ITiCSE '18, New York, NY, USA, 2018. ACM.

[32] K. Quille, S. Bergin, and A. Mooney. PreSS \#, A Web-Based Educational System to Predict Programming Performance. International fournal of Computer Science and Software Engineering (IJCSSE), 4:178-189, 2015.

[33] K. Quille, N. Culligan, and S. Bergin. Insights on gender differences in cs1: A multi-institutional, multi-variate study. In Proceedings of the 2017 ACM Conference on Innovation and Technology in Computer Science Education, ITiCSE '17, pages 263-268, New York, NY, USA, 2017. ACM.

[34] K. Quille, R. Faherty, S. Bergin, and B. A. Becker. Second level computer science: The irish k-12 journey begins. In Proceedings of the 18th Koli Calling International Conference on Computing Education Research, Koli Calling '18, pages 22:1-22:5, New York, NY, USA, 2018. ACM

[35] V. Ramalingam, D. LaBelle, and S. Wiedenbeck. Self-efficacy and mental models in learning to program. In ACM SIGCSE Bulletin, volume 36, pages 171-175. ACM, 2004.

[36] V. Ramalingam and S. Wiedenbeck. Development and Validation of Scores on a Computer Programming Self-Efficacy Scale and Group Analyses of Novice Programmer Self-Efficacy. Fournal of Educational Computing Research, 19(4):367381, Dec. 1998. 00168

[37] M. Román-González, J.-C. Pérez-González, J. Moreno-León, and G. Robles. Extending the nomological network of computational thinking with non-cognitive factors. Computers in Human Behavior, 80:441 - 459, 2018. 00016.

[38] M. Rosenberg. Society and the adolescent self-image. Princeton University Press, Princeton, New Jersey, 1965.

[39] M. Rosenberg. Society and the adolescent self-image, volume 11. Princeton university press Princeton, NJ, 1965.

[40] D. Seehorn. CSTA K-12 Computer Science Standards, Computer Science Teachers Association. ACM, New York, 2011

[41] R. J. Shavelson and R. Bolus. Self concept: The interplay of theory and methods. fournal of Educational Psychology, 1982.

[42] E. M. Skaalvik and S. Skaalvik. Dimensions of Teacher Self-Efficacy and Relations With Strain Factors, Perceived Collective Teacher Efficacy, and Teacher Burnout. fournal of Educational Psychology, 2007.

[43] E. M. Skaalvik and S. Skaalvik. Teacher self-efficacy and teacher burnout: A study of relations. Teaching and Teacher Education, 2010

[44] U. Trautwein, O. Lüdtke, O. Köller, and J. Baumert. Self-esteem, academic selfconcept, and achievement: How the learning environment moderates the dynamics of self-concept. Fournal of Personality and Social Psychology, 2006.

[45] M. Tschannen-Moran, A. W. Hoy, and W. K. Hoy. Teacher efficacy: Its meaning and measure. Review of educational research, 68(2):202-248, 1998.

[46] U.S. Department of Education National Center for Education Statistics. Characteristics of public school teachers, 2018

[47] R. Vivian and K. Falkner. A survey of Australian teachers' self-efficacy and assessment approaches for the K-12 digital technologies curriculum. In Proceedings of the 13th Workshop in Primary and Secondary Computing Education, Potsdam, Germany, 2018. ACM.

[48] S. Wiedenbeck, D. Labelle, and V. N. Kain. Factors affecting course outcomes in introductory programming. In $P P I G$, page 11, 2004.

[49] A. Yadav, S. Gretter, S. Hambrusch, and P. Sands. Expanding computer science education in schools: understanding teacher experiences and challenges. Computer Science Education, 26(4):235-254, 2016.

[50] E. Yukselturk and S. Altiok. An investigation of the effects of programming with Scratch on the preservice IT teachers' self-efficacy perceptions and attitudes towards computer programming. British fournal of Educational Technology, 2017.

[51] D. Zingaro. Peer Instruction Contributes to Self-efficacy in CS1. In Proceedings of the 45th ACM Technical Symposium on Computer Science Education, SIGCSE '14, pages 373-378, New York, NY, USA, 2014. ACM. 00044 event-place: Atlanta, Georgia, USA.

[52] A. N. Çoklar and A. Akçay. Evaluating Programming Self-Efficacy in the Context of Inquiry Skills and Problem-Solving Skills: A Perspective from Teacher Education. World Journal on Educational Technology: Current Issues, 10(3):153-164, 2018. 00002 . 